RESEARCHPAPER

\title{
Development of Ocimum sanctum (Tulsi) incorporated mango leather to enhance the sensory quality and storage stability
}

\author{
M.B. JABEZ ${ }^{1}$, S.K. MATHANGHI ${ }^{2}$, K. SUDHA ${ }^{1}$ AND M.K.S. VENKATESH ${ }^{1}$ \\ ${ }^{1}$ College of Food and Dairy Technology, Tamil Nadu Veterinary and Animal Sciences University, CHENNAI (T.N.) \\ INDIA \\ ${ }^{2}$ Department of Food Engineering, College of Food and Dairy Technology, Tamil Nadu Veterinary and Animal Sciences \\ University, CHENNAI (T.N.) INDIA \\ Email : mathanghi@tanuvas.org.in; brightonbtech@gmail.com; ksudhai@tanuvas.org.in
}

Article Info : Received : 14.01.2015; Revised : 25.02.2015; Accepted : 10.03.2015

Mango fruit leather was prepared by incorporation of Ocimum sanctum (Tulsi) for better textural and sensory properties. The mango fruit leather was incorporated with the leaf extract of $O$. sanctum at different concentrations of 5, 10,15 and 20 percentages. The natural antioxidants present in the $O$. sanctum leaf extracts that was incorporated in the fruit leather showed extended shelflife over three months when compared with control, without any added preservatives at ambient temperature. Also the storage stability of the product was studied under two flexible packages of polypropylene and polyester out of that the products packed in polypropylene showed better storage stability.

Key words : Mango fruit leather, $O$. sanctum, Polyester, Polypropylene

How to cite this paper : Jabez, M.B., Mathanghi, S.K., Sudha, K. and Venkatesh, M.K.S. (2015). Development of Ocimum sanctum (Tulsi) incorporated mango leather to enhance the sensory quality and storage stability. Asian J. Bio. Sci., 10 (1) : 71-74. 